\title{
Protein film voltammetry: electrochemical enzymatic spectroscopy. A review on recent progress
}

\author{
Rubin Gulaboski • Valentin Mirčeski • Ivan Bogeski • \\ Markus Hoth
}

Received: 8 March 2011 / Accepted: 26 March 2011 /Published online: 4 May 2011

(C) Springer-Verlag 2011

\begin{abstract}
This review is focused on the basic principles, the main applications, and the theoretical models developed for various redox mechanisms in protein film voltammetry, with a special emphasis to square-wave voltammetry as a working technique. Special attention is paid to the thermodynamic and kinetic parameters of relevant enzymes studied in the last decade at various modified electrodes, and their use as a platform for the detection of reactive oxygen species is also discussed. A set of recurrent formulas for simulations of different redox mechanisms of lipophilic enzymes is supplied together with representative simulated voltammograms that illustrate the most relevant voltammetric features of proteins studied under conditions of square-wave voltammetry.
\end{abstract}

Keywords Redox enzymes · Electrochemistry - Modified electrodes $\cdot$ Reactive oxygen species $\cdot$ Mathematical modelling

Dedicated to the 75th birthday of Dr. Nina Fjodorovna Zakharchuk

R. Gulaboski $(\triangle)$

Faculty of Agriculture, Department of Chemistry,

Goce Delčev University,

Štip, Macedonia

e-mail: rubin.gulaboski@ugd.edu.mk

V. Mirčeski

Faculty of Natural Sciences and Mathematics, Institute of Chemistry, "Ss Kiril i Metodij" University,

Skopje, Macedonia

I. Bogeski $\cdot$ M. Hoth

Faculty of Medicine, Department of Biophysics,

University of Saarland,

66421 Homburg, Germany

\section{Introduction}

Life on earth depends almost exclusively on occurrence of redox (redox=reduction oxidation) reactions, which are reactions involving the exchange of electrons between two or more neighboring biochemical systems. The electron chargetransfer reactions are responsible for the function of many proteins and other redox-active compounds in various biochemical systems. This is well-known in bioenergetics, where photosynthesis and respiration are fundamental processes in which energy conversion takes place through a complex sequence of electron transfer reactions involving different redox proteins. However, electron transfer also takes place in many other biological processes ranging from cell defense to gene control. Since many diseases are mainly associated with malfunctioning redox biochemistry in humans, the understanding of these processes has also a big medical significance. One of the fundamental aspects of biological redox chemistry is the physiological importance of the electron transfer organized by proteins in the living systems. Thus, a lot of efforts have been made in the last 30 years to link the thermodynamics and kinetics of electron transfer with the structural and thermodynamic features of various proteins. Since the fundamental principles of electron transfer processes are relatively well understood, the current interest in bioelectrochemistry is focused largely on the mechanisms by which electron transfers are linked to other important physiological functions. Within all "in vivo" redox processes, two or more redox-active species react with each other in a way of exchanging electrons between them. For the relatively small biochemical systems (small molecules), the voltammetric methods are a common tool of choice that provide insight into the thermodynamics and kinetics of electron transfer reactions, while also giving valuable information about the 
mechanisms of interactions between such biochemical systems. In the case of proteins, the use of voltammetry as a technique to understand their redox chemistry is not an easy task. The main problems arise from the huge protein size and the presence of big "electroinactive" lipophilic tail which impede the "access" of electrons to the protein's redox-active site(s) through their insulating features.

Nearly 15 years ago, a new voltammetric methodology had been developed, which allows insight into the redox chemistry of various lipophilic redox-active proteins [1-5]. The original name of this technique coined by Armstrong is "protein film voltammetry" (PFV) [1]. This methodology provides access to a wealth of information on the reactions of redox-active sites in proteins in a quite simple manner. By this technique, a given protein is attached on an electrode surface mainly by self-assembling from the aqueous electrolyte in which the protein is initially dissolved. The electrode surface on which a protein is adsorbed actually acts as a surrogate partner that mimics the biological redox processes of the proteins. By applying a controlled potential to the protein-modified electrode, the redox features of the adsorbed protein can be monitored by using various voltammetric techniques. A potentiostat is commonly used to change the potential energy of the electrode which drives electrons onto or removes electrons from the protein redox-active sites. By applying cyclic voltammetry (CV) over a wide range of scan rates, for example, and exploiting the ability to cycle or pulse the electrode potential between defined values, valuable data about the protein's physiological activity can be obtained. The obtained data are commonly analyzed in terms of plots of peak potentials, peak currents, or half-peak widths against the applied scan rates. By such an analysis, one can obtain relevant thermodynamic and kinetic information about the physiological functions coupled to protein redox activity. In this review, we will focus on the main achievements and challenges of this methodology, particularly when combined with advanced voltammetric techniques as a square-wave voltammetry (SWV). A special part will be dedicated to the application of PFV for studying coupled redox reactions of relevant enzymes. In addition, we will discuss recent theoretical models for various electrode mechanisms under the conditions of SWV, where we offer a simple way to obtain reliable thermodynamic and/or kinetic information on the redox reactions of studied proteins.

\section{Performing an experiment in protein film voltammetry}

Protein film voltammetry is a unique and powerful technique that provides relevant thermodynamic and kinetic information obtained from a single voltammetric experiment. PFV is quite a simple approach designed to studying the redox features of lipophilic (or slightly water soluble) enzymes. As a first step, a given (redox) protein has to be adsorbed as a thin film on the surface of a suitable electrode. The adsorption of the protein at the electrode surface commonly occurs through selfassembling of the protein from the protein-containing electrolyte solutions in which the working electrode is submerged. A simple schematic representation of a simple PFV setup at a modified electrode surface is given in Fig. 1. Such proteinmodified electrode can be probed by a variety of electrochemical techniques by applying a driving force (potential
Fig. 1 Scheme of a common protein film voltammetric setup

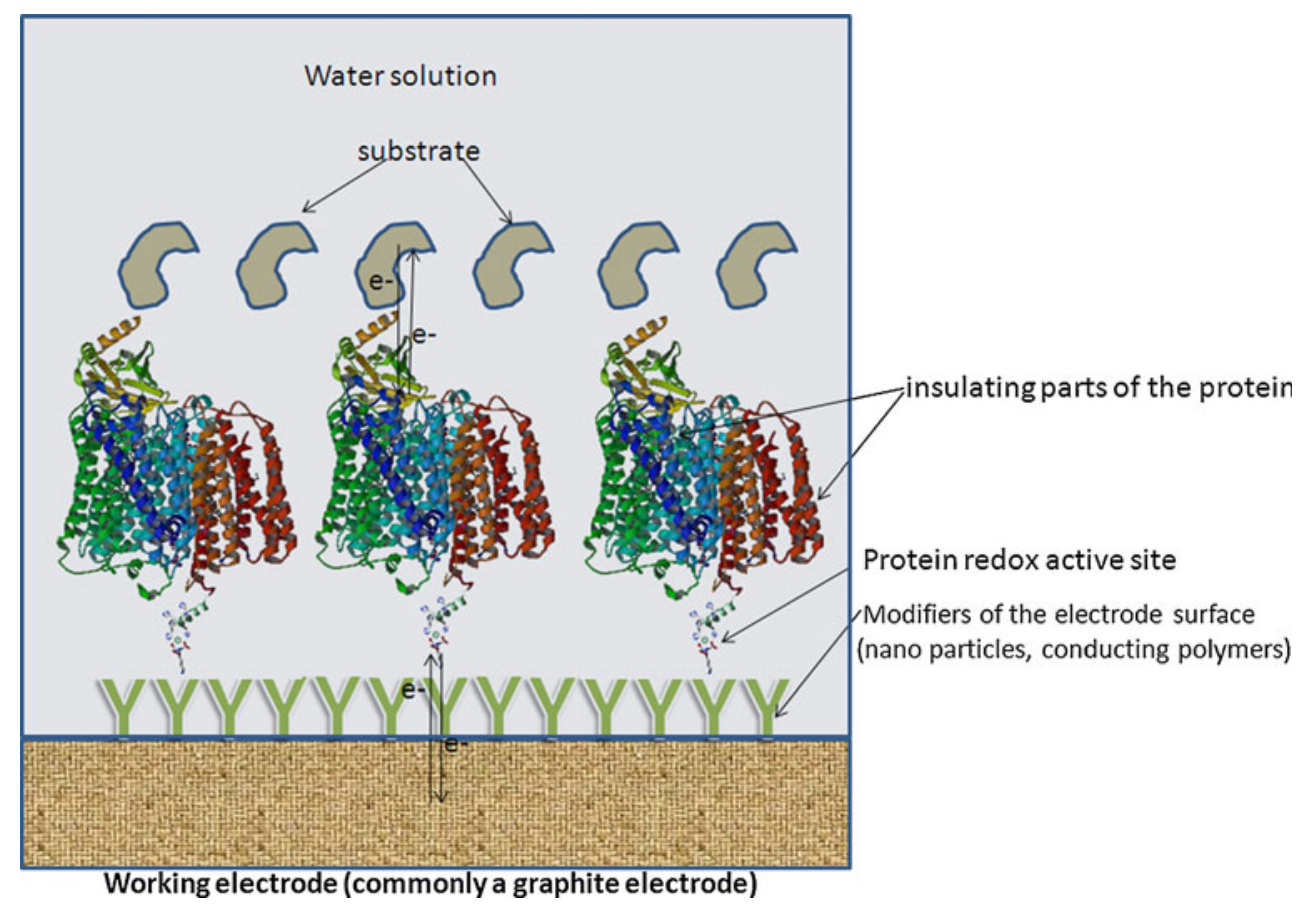


difference) in order to move electrons into and out of the protein. The movement of the electrons between the electronic conductor (electrode) and the active center of the redox-active protein is instrumentally detected as a currentpotential profile having specific features depending on the measuring time and the applied potential. From the features of the voltammetric outputs, one can obtain information about the thermodynamic and kinetic parameters of the electron transfer process between the electrode and the redox sites of the proteins [1, 4] and in addition, an insight into the mechanism of protein interactions with the given substrates [5-10]. To do this, a good theoretical background of the ongoing electrode mechanism is required. In order to mimic the physiological activity in the living systems, the native structural and reactive features of the redox proteins must be retained when adsorbed onto the electrode surface. Hitherto, the main part of the PFV experiments is performed around neutral $\mathrm{pH}$ and at temperatures between 20 and $40{ }^{\circ} \mathrm{C}$, thus mimicking physiologicallike conditions. The minimization of the adsorptive surface denaturation of proteins and keeping the electrode surface as clean as possible, are essential factors which facilitate the direct electron exchange between an electrode and the redox site of the proteins. Several metal electrodes coated with metal oxides, carbon electrodes coated with organic monolayers, and pyrolytic graphite edge plane electrodes are currently known as the most suitable surfaces fulfilling these requirements [5, 11-19]. In the last few years, basal plane pyrolytic graphite electrodes, glassy carbon electrodes, and even unmodified metallic electrodes have been extensively used in PFV [5].

Pyrolytic graphite edge plane electrodes are especially suitable for PFV. These electrodes contain a big fraction of the negative carboxylate groups in their three-dimensional structure that can interact electrostatically (or by hydrogen bonds) with positively charged amino acids of many proteins [12-19]. This contributes to better sticking of many proteins to the electrode surface.

Despite many efforts for improving the performances of PFV, the redox activity of many redox proteins cannot be probed because the direct electron exchange with the electrodes is difficult to be achieved. The main cause for their redox inactivity is related to the insulating features of their side chains. In such cases, there is a common scenario of co-adsorbing the proteins with some organic linkers like polymixins, aminocyclitols, alkylthiols, and some other compounds that are known as good electron shuttling systems [5]. Such modifications usually lead to an increase of the electrochemical reversibility of the electron exchange between the proteins and the electrodes. Enzymes can also be trapped into some conducting polymer network built from polypyrrole, polyaniline, polythiophene, or polyindole that are developed on an electrode surface by electrochem- ical polymerization [5, 13-15]. Different strategies of polymerization have been developed in order to enhance the rate of the electron exchange between the electrode and the active sites of the proteins, and these are described elsewhere in more detail [5]. In recent years, there has been an increased interest in applying the nanoparticle strategy as a tool for enhancing the electrochemical reversibility of many proteins. The very high electrical conductivity, good chemical stability, and structural robustness of carbon nanotubes are crucial physical parameters permitting these materials to be exploited in the electrochemistry of many redox proteins [16-19]. A quite promising electrode for studying various enzymes is the recently applied diamond electrode [20]. Nanocrystalline diamond or ultrananocrystalline diamond thin films have been found quite suitable for a large variety of substrates [21]. We must note, however, that due to the very high price of this electrode, its use in PFV has been quite limited so far. Many of the aforementioned applications of enzymes in PFV have involved interesting biosensor construction for detecting various substrates on nanomodified electrodes, and some of these will be discussed in detail in the subsequent sections.

\section{Representative examples of enzymes studied with protein film voltammetry}

Since the establishment of PFV some 15 years ago, the number of published papers on this topic increases continuously. At the moment, there are over 650 papers and several monographs dedicated exclusively to the enzyme redox chemistry studied with PFV setups. Despite this increasing interest in using PFV, the number of considered proteins is quite limited, and it does not exceed the total of 40 at the moment. However, it is important to emphasize that most of the proteins considered in the published papers are extremely important due to the various functions they cover in the living cells. Some of the well-studied examples include cytochrome P450, other haem-containing proteins like hemoglobin, myoglobin, cytochrome $\mathrm{C}$, and furthermore glucose oxidase, PS-I and PS-II photosystems, the proteins from the electron transfer chain, several hydrogenases, some Mo-containing proteins and various $\mathrm{Fe}-\mathrm{S}$, and other metal-containing proteins (mainly with $\mathrm{Ni}-\mathrm{Fe}, \mathrm{Mn}$ or $\mathrm{Cu}$ as redox centers). In Table 1, we summarize a considerable number of relevant enzymes studied with PFV mainly within the last 6-8 years. We summarize insights to some of the thermodynamic and kinetic parameters of their redox transformation as well as the type of electrodes at which PFV has been achieved for a particular enzyme (see Table 1). Several comprehensive reviews dedicated to the PFV achievements before 2003 can 


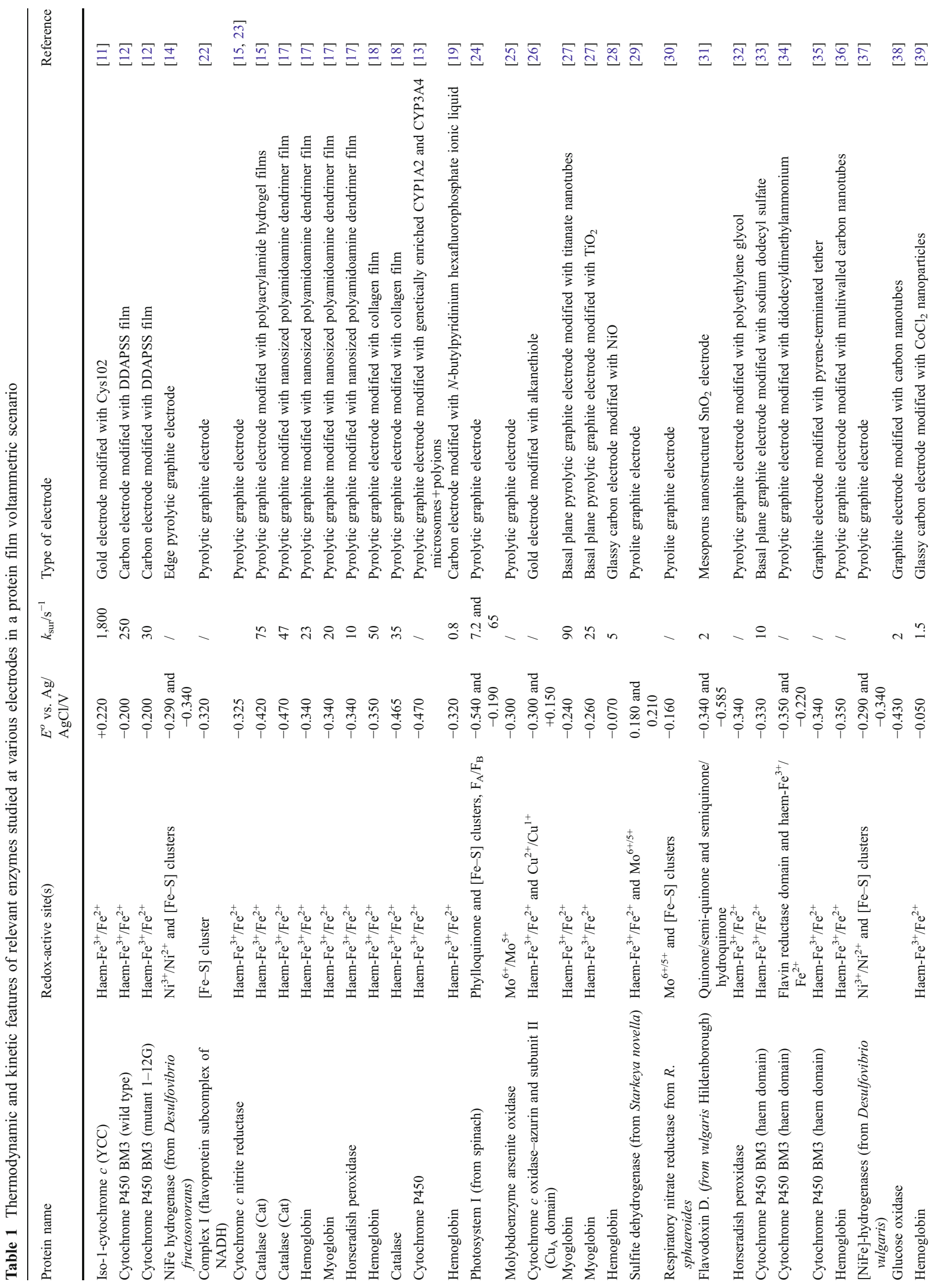


be found elsewhere $[1-5,10]$, and we skipped most of those studies in our review.

\section{Overview of the redox mechanisms considered in square-wave PFV}

Protein film voltammetry is a powerful methodology that enables direct electrochemical measurements of redox enzymes and proteins, and it often provides precise and comprehensive information on complicated reaction mechanisms. We gain information in respect to the reaction mechanisms of a given protein by monitoring the current of the instrumental outputs (voltammograms) in real time as a function of the applied driving force (i.e., the applied potential). At the moment, two challenges are intrinsic to protein film voltammetry: (1) to learn how to adsorb a given protein in a native and active configuration on the electrode surface and (2) to understand and interpret the voltammetric results on both qualitative and quantitative level. The latter is dependent on developing theoretical models simulated for the particular electrode mechanism and a making correlation of theoretical results with the experimental findings. Most of the theories comprising various reaction mechanisms in PFV are developed under conditions of cyclic voltammetry $[1-5,10]$. However, alongside cyclic voltammetry, the SWV is also a very powerful voltammetric method for studying redoxactive enzymes and proteins [27, 46-55]. The potential modulation in SWV consists of a train of equivalent anodic and cathodic potential pulses superimposed on a staircase potential ramp [8]. The SWV can be understood as a repetitive double step chronoamperometric experiment, conducted at each step of the staircase ramp. Over the potential window defined by the limits of the staircase potential ramp, the electrode reaction is repetitively forced in both cathodic and anodic directions, thus providing intrinsic information on the mechanism of the electrode reaction. In this regard, SWV is complementary to CV. On the other hand, owing to the pulse nature of the technique, SWV effectively discriminates against the charging current, thereby extracting only the faradaic component of the overall electrochemical response. It should be also stressed that the critical time window over which the electrode reaction is investigated in both the cathodic and anodic mode is defined by the frequency of the potential modulation $(f)$, which is the inverse value of the duration of a single potential step of the staircase $\operatorname{ramp}\left(\tau_{\mathrm{s}}\right)$, i.e., $f=1 / \tau_{\mathrm{s}}$. As the typical frequency range of the modern instrumentation used for SWV is between 10 and 2,000 Hz, the critical time window of the experiment is $0.5 \mathrm{~ms} \leq \tau>_{\mathrm{s}} \leq 100 \mathrm{~ms}$. Obviously, SWV is a rather fast voltammetric method, which is particularly appealing for kinetic measurements in PFV. For the sake of comparison, let us give the following example: an SWV 
experiment at $f=100 \mathrm{~Hz}$ corresponds to a $\mathrm{CV}$ experiment conducted at the sweep rate of $60 \mathrm{~V} / \mathrm{s}$, assuming a $0.300-\mathrm{V}$ potential difference between the initial and the switching potential. For most experimental systems, SWV at $f=100 \mathrm{~Hz}$ provides undistorted, high-quality voltammetric data, whereas the $\mathrm{CV}$ experiment at $60 \mathrm{~V} / \mathrm{s}$ is still state of the art.

The theoretical background for the SWV of surface electrode processes, where the electroactive form is confined to the electrode surface in a form of a monolayer is well developed, and it can be effectively utilized in PFV. Over the last decade, significant efforts have been undertaken in modeling and simulations of the surface electrode processes, revealing that SWV is particularly appealing for mechanistic, kinetic, and thermodynamic characterization of surface electrode processes, including proteins and enzymes [27, 46-55]. So far, a plethora of electrode mechanisms have been considered, including simple surface electrode reactions [46, 47, 56-61], surface reactions with uniform interactions [62], surface electrode reactions coupled with a preceding [63] or following chemical reaction [64], surface catalytic mechanisms [65, 66], twostep surface reactions [67, 68], and two-step reactions coupled with an intermediate chemical step (ECE - or electrochemical-chemical-electrochemical reaction scheme) [69]. The list of surface mechanisms can be easily extended, as the mathematical modeling of surface processes, although not easy, is yet simpler than in the case of common diffusion controlled processes. Moreover, the already existing, rich theory for surface mechanisms under the conditions of $\mathrm{CV}[1-5,10]$ can be easily adopted for SWV. In the Appendix, we give a list of recurrent formulas for the simulation of the most frequently encountered electrode mechanisms which can be easily implemented in various software packages. The formulas given in the Appendix are derived based on the Butler-Volmer electrode kinetics, although there are few studies of merit where the surface processes of immobilized proteins have been modeled on the basis of the Marcus kinetic theory to account for the intricate voltammetric behavior at large overpotentials [47, 50]. Rusling et al. [47] first modeled a surface electrode reaction under conditions of SWV on the basis of the Markus kinetic theory, in order to study myoglobin, incorporated into thin films of didodecyldimethylammonium bromide on the surface of a basal plane pyrolytic graphite electrode. Later on, Armstrong et al. [50] utilized the Marcus theory to model the surface electrode reaction of azurin, also called the blue copper protein.

The square-wave (SW) voltammetric response of an immobilized protein is expected to exhibit rather complicated properties, even in the case of a simple electron transfer process. The most remarkable features of almost all quasireversible surface electrode reactions are the "quasireversible maximum" [8] and the "splitting of the net SW peaks" [70].
The quasireversible maximum refers to the parabolic dependence of the ratio $\Delta I_{\mathrm{p}} / f$ vs. frequency of the potential modulation $f$, where $\Delta I_{\mathrm{p}}$ is the net peak current. The origin and the physical meaning of the quasireversible maximum is well understood [8], and its importance stems from the fact that the critical frequency associated with the maximum of the parabola is directly proportional to the standard rate constant of the electrode reaction studied. An important advantage is that the quasireversible maximum is hardly sensitive to the number of electrons involved in the electrode reaction, $n$, thus enabling kinetic measurements without knowing the latter parameter. Next to the quasireversible maximum, the splitting of the net SW peak is the feature of fast surface electrode reactions $[8,70]$. At certain critical amplitudes of the potential modulation, the single net SW peak splits into two peaks, symmetrically located around the formal peak potential of the system. For given parameters of the potential modulation, the potential separation between split peaks is highly sensitive to the standard rate constant and the number of electrons exchanged. The important advantage of the splitting is that it can be utilized for kinetic measurements of very fast surface processes only by altering the amplitude of the potential modulation, at a fixed low frequency, i.e., at a low sweep rate. Armstrong et al., for example [50], emphasized the utility of the splitting of the SW response under large amplitudes for the estimation of the reorganization energy and maximum rate constant in the case of azurin, adsorbed on edge plane pyrolytic graphite and gold electrodes modified with different self-assembled monolayers of various 1-alkenthiols. In Fig. 2, we provide a set of simulated voltammograms corresponding to relevant mechanisms in PFV studied under conditions of square-wave voltammetry. The readers can certainly benefit from the plethora of voltammograms that show how a particular mechanism in the PFV will be portrayed via the forward-backward and the net current components of the SW voltammograms.

Fig. 2 a Simple surface redox reaction. Effect of the electron transfer kinetic to the features of simulated square-wave voltammograms. The conditions for the simulations were as follows: electron transfer coefficient $\alpha=0.5$, square-wave amplitude $E_{\mathrm{sw}}=40 \mathrm{mV}$, potential step $\mathrm{d} E=5 \mathrm{mV}$, and temperature $T=298 \mathrm{~K}$. b Surface $\mathrm{C}_{\mathrm{r}} \mathrm{E}$ mechanism: Effect of the chemical kinetics to the features of simulated squarewave voltammograms. The value of the equilibrium constant was $K=$ 0.1 , while the value of the dimensionless kinetic parameter was $\omega=1$. c Surface $\mathrm{EC}_{\mathrm{i}}$ mechanism: Effect of the chemical kinetics to the features of simulated square-wave voltammograms. The value of the dimensionless kinetic parameter was $\omega=1$. d Surface catalytic EC': Effect of the catalytic parameter to the features of simulated voltammograms. The value of the dimensionless kinetic parameter was $\omega=1$. e Surface two-step EE mechanism. Effect of the electron transfer kinetics of both steps to the features of simulated square-wave voltammograms. f Surface ECE mechanism: Effect of the chemical step to the features of simulated voltammograms. The value of the dimensionless kinetic parameters of both electron transfer steps were $\omega_{1}=\omega_{2}=1$. Other conditions were the same as those in Fig. 2a 

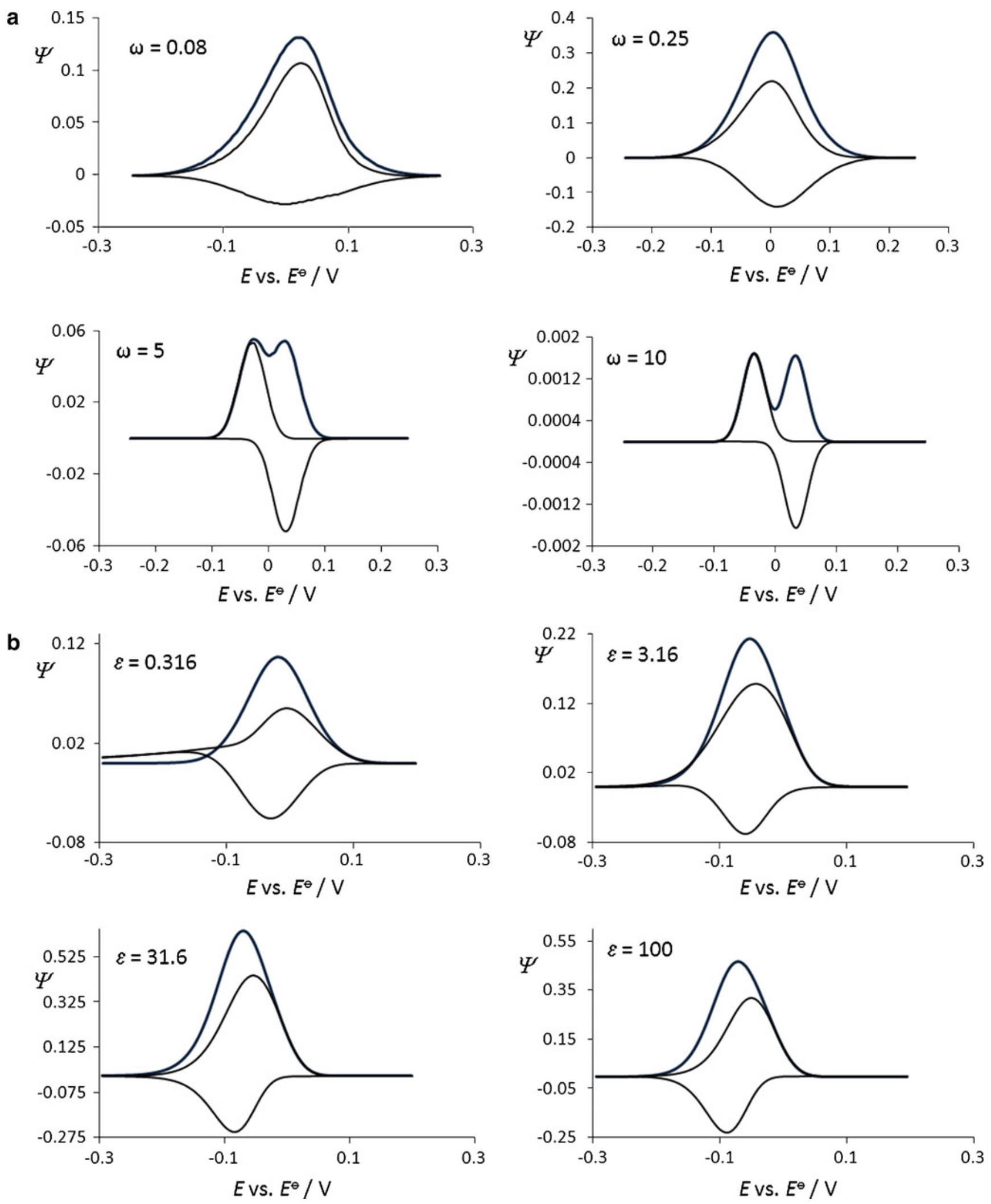

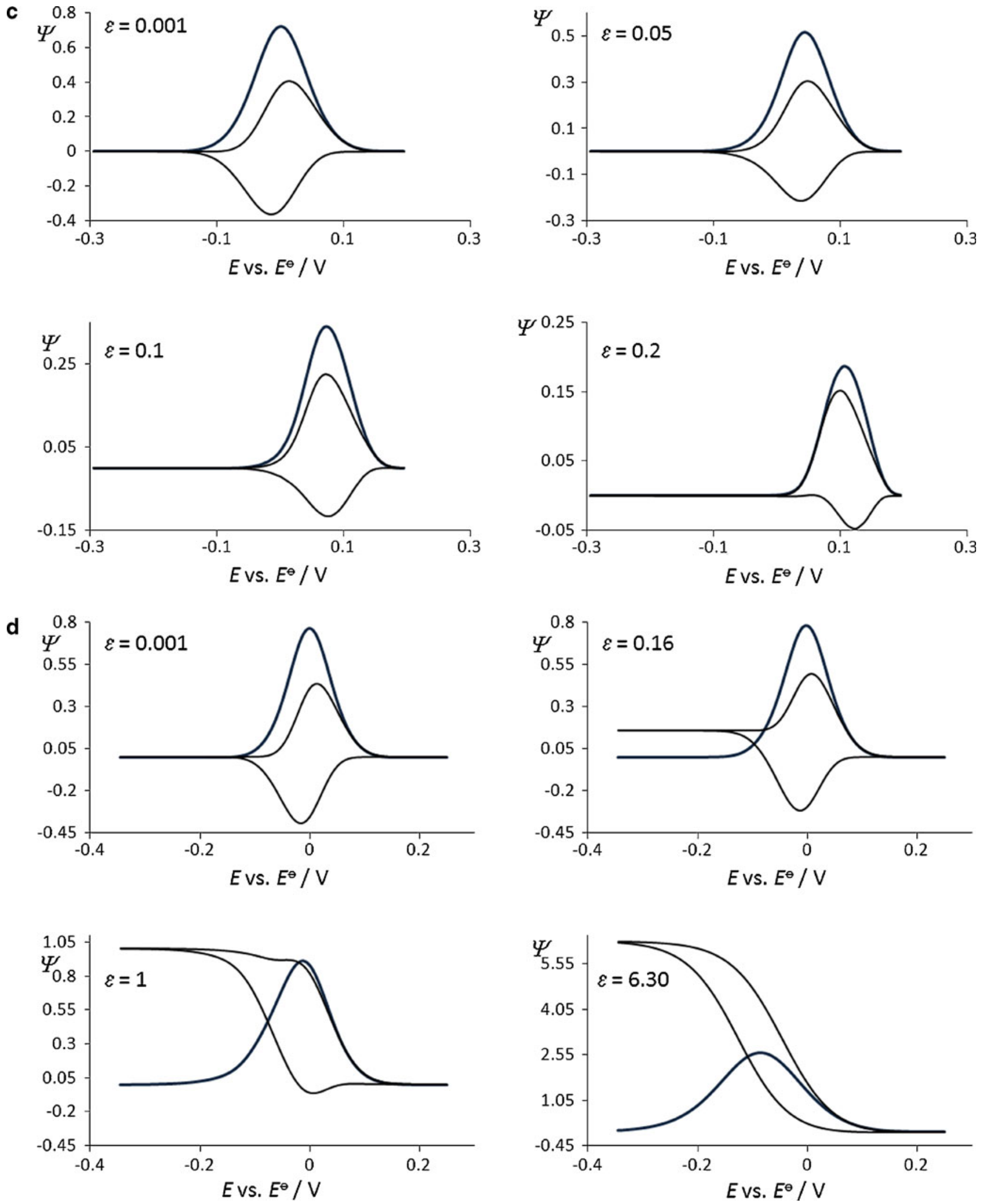

Fig. 2 (continued) 

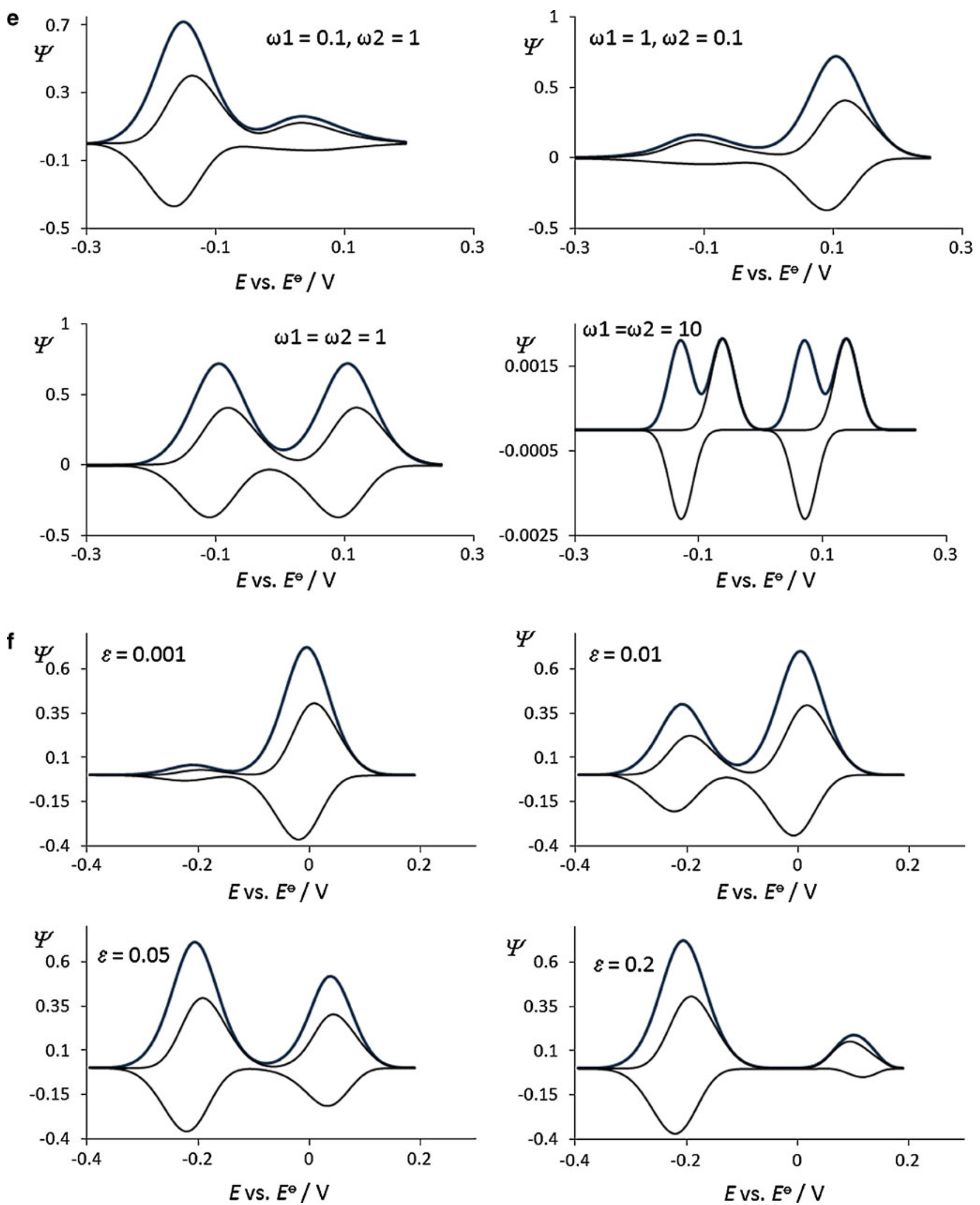

Fig. 2 (continued)

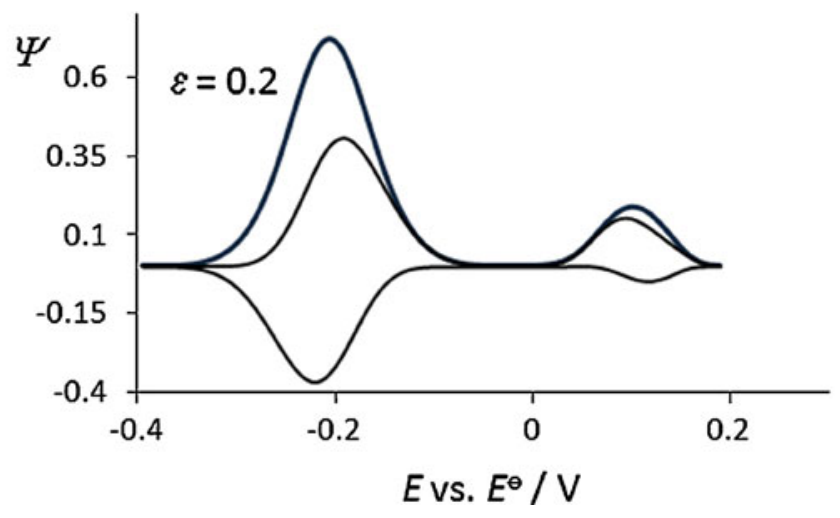




\section{Protein film voltammetry of common enzymes as a platform for designing electrochemical sensors for various reactive oxygen species}

All cells commonly generate energy under aerobic conditions via the reduction of molecular oxygen $\left(\mathrm{O}_{2}\right)$ to water. By gaining their energy from the oxygen's reduction, the aerobic organisms get, at the same time, quite susceptible to the various damaging effects of the so-called reactive oxygen species (ROS). The ROS are inevitably created during the metabolism of oxygen, especially by its incomplete reduction with the redox systems engaged in the mitochondrial electron transfer chain. ROS generated in the living cells can roughly be classified into two groups: radicals and non-radicals. In the "radical group" one classifies the highly reactive species such as hydroxyl radical $(\mathrm{OH} \cdot)$, superoxide ion radical $\left(\mathrm{O}_{2}{ }^{-}\right)$, peroxyl (ROO·), nitric oxide radical (NO·), and alkoxyl radicals (RO-). A common feature of the compounds belonging to the radical group is the existence of one unpaired electron that makes them highly reactive. In the second group of "non-radical" ROS, one finds compounds produced in relatively high concentrations in the living cell such as hydrogen peroxide $\left(\mathrm{H}_{2} \mathrm{O}_{2}\right)$, hypochloric acid $(\mathrm{HClO})$, and various organic peroxides. Reactive oxygen species produced during different electron transfer reactions in vivo are usually considered to be highly harmful to cells. Most of the aforementioned ROS are short-living species that are keen to react very quickly with redox counter partners from their surroundings. The half-lives for most of the ROS from the "radical group" range between $10^{-3}$ and $10^{-10} \mathrm{~s}$, while the half-life of the ROS from the non-radical group is typically much higher (it ranges between several seconds to several hours) [71]. The very high reaction rates of ROS with many biological compounds from their surroundings make the direct detection of ROS in biological systems a difficult task. In the past 10 years, the protein film voltammetry has emerged as a viable electrochemical tool for the detection of various ROS. In most of the PFV studies, the authors have explored haemcontaining proteins as catalase [16-19], hemoglobin and myoglobin [17, 18, 36, 39-41, 44], cytochrome P450 [13, 34], and horseradish peroxidase [32] as platforms for the detection of oxygen, hydrogen peroxide, trichloroacetic acid, and nitrites. Although good progress has been made in the electrochemical detection of ROS by protein film voltammetry, it is worth mentioning that better methods for quantification of ROS are still required. This is because the very small specificity and non-selectivity of the enzymes used for ROS detection. In addition, the enzymes used as a platform for ROS detection are sensitive to rather big concentrations of the substrates (i.e., the enzyme sensors can work only in the concentration regions of ROS of over $50 \mu \mathrm{M}$ ), which make their use for the direct detection of ROS in the cells quite limited. Nonetheless, the use of PFV for ROS detection will be developed further, mainly because of the simplicity of achieving "in vivo" detection of ROS by a very simple experimental PFV setup.

\section{Outlooks for the future}

Protein film voltammetry is a relatively novel methodological approach that allows direct probing of the electrochemistry of redox enzymes and proteins, while providing a plethora of information on complex reaction mechanisms of various waterinsoluble proteins. After the introduction of PFV [1-5], it became possible to study the redox features of many enzymes in a common three-electrode voltammetric setup. In this way, much valuable information about the physiological functions of various enzymes has been collected in the last 15 years. Although significant progress has been made, the number of considered enzymes in the PFV is still quite limited, and it does not exceed a total of 40 so far. The main reason for this is due to the hindered electron exchange between the redox centers of many lipophilic proteins with the electrode materials used in PFV. As many proteins contain long side chains having insulating features, efforts are permanently made to minimize the effect of the protein's side chains by modifying the working electrodes in different manners [5]. Though various modifications of the electrode surfaces have been presented so far [5], the search for a "universal" electrode material that has satisfying electron exchanging features towards different enzymes still goes on. In this respect, the diamond electrode $[20,21]$ is probably the most promising material but unfortunately very expensive. While plenty of papers have shown that PFV can be successfully exploited as a sensing tool for ROS detection [5, 13, 16-19, 36, 39-41, 44], there are still a lot of limitations to employ this technique for the direct detection and determination of ROS in the cells. The cause is found in the low selectivity of the PFV setup and in its low sensitivity at physiological ROS concentrations. Positive signals in exploring the PFV as a tool for "in vivo" determination of ROS in the cells come from the single enzyme electrochemistry methodology [72]. By employing scanning electrochemical microscopy to a single enzyme by using nano-electrodes, one gets reliable information about the physiological activity of a given enzyme. This methodology [73] appears to be a quite promising application of PFV in living cells, and most efforts will be dedicated to develop this technique in the coming years. Nevertheless, the future progress of PFV will also largely depend on the development of new theoretical models that will help in understanding the complex behavior of many enzymes. In particular, the theoretical models for proteins containing multiple redox centers, or redox centers that undergo successive redox transformation [5, 52, 74, 75], are needed to elucidate the complex physiological functions of such 
proteins. So far, there is clearly a lack of theories considering the voltammetric features of such proteins [76].

Acknowledgments R.G. thanks the Alexander von Humboldt Foundation for providing a Return postdoctoral fellowship. This work is also supported by the Alexander von Humboldt Foundation via the joint German-Macedonian project from the Research Group Linkage Programme 3.4-Fokoop-DEU/1128670 (to V.M., R.G. I.B., and M.H.). M.H. also acknowledges the support by the Deutsche Forschungsgemeinschaft (SFB 530, SFB 894, GK 845, GK 1326).

\section{Appendix}

The recurrent formulas given in the following table are derived with the aid of the step-function method for solving integral equations [77], assuming that electrode reactions obey Butler-Volmer kinetic formalism. An oxidative electrode reaction is assumed, in which at the beginning of the experiment (i.e., $t=0$ ) only the reduced form $(R)$ of the protein is present in a form of a monolayer at surface

Table 2 Recurrent formula for calculating the square-wave voltammograms of various surface electrode mechanisms relevant for adsorbed proteins under conditions of square-wave voltammetry

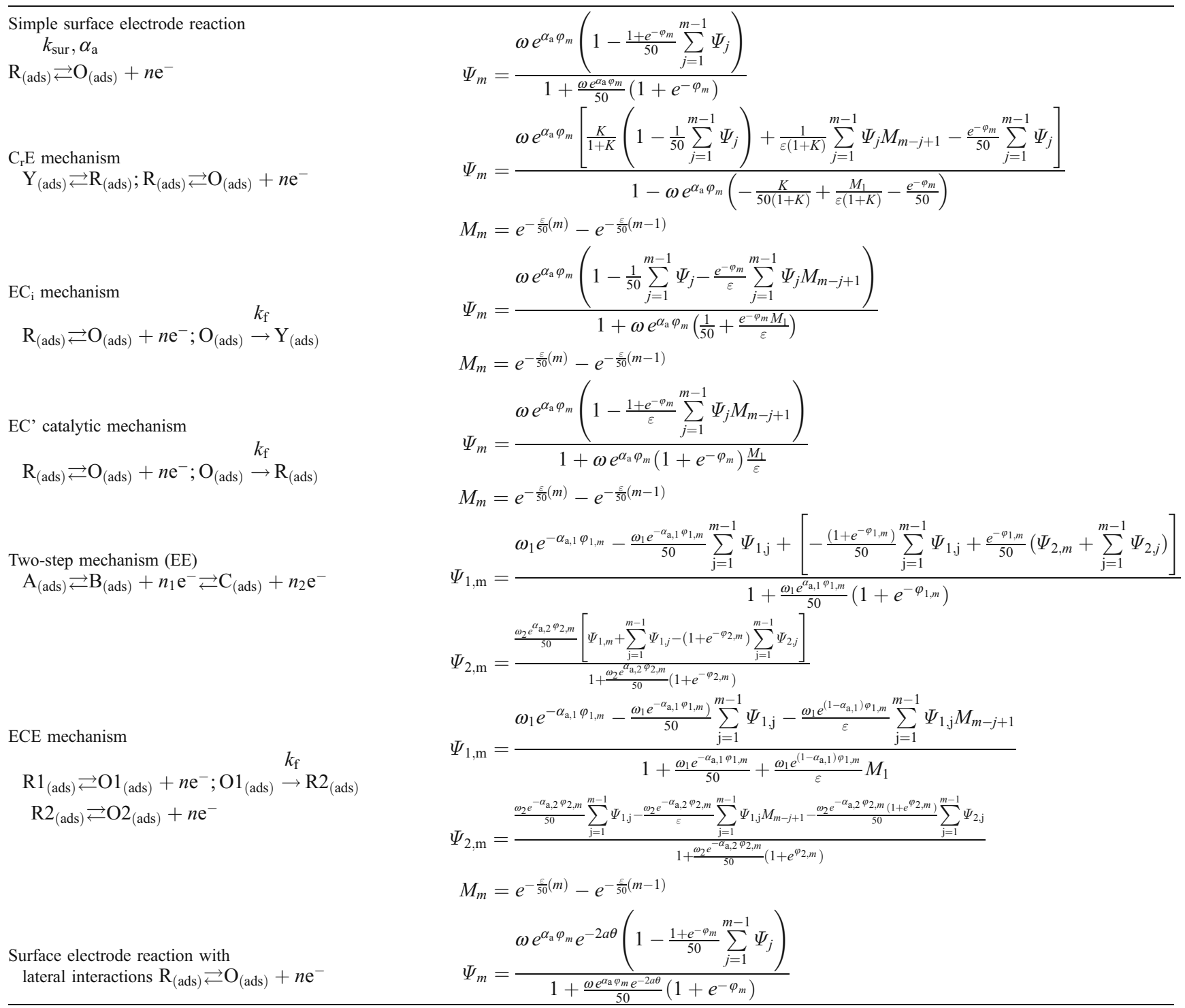

In Table 2, $\omega=\frac{k_{\text {sur }}}{f}$ is the dimensionless electrode kinetic parameter, where $k_{\text {sur }}$ is the surface standard rate constant in units of per second; for the mechanism with uniform lateral interactions between immobilized species, $a$ is the Frumkin interaction parameter, which is positive for attractive forces and negative for repulsive forces, $\theta=\frac{\Gamma}{\Gamma_{\max }}$ is the fraction of the electrode covered with deposited material, and $\Gamma_{\max }$ is the maximal surface coverage; For the $\mathrm{C}_{\mathrm{r}} \mathrm{E}$ mechanism, $K=\frac{k_{\mathrm{f}}}{k_{\mathrm{b}}}$ is the equilibrium constant of the preceding chemical reaction, where $k_{\mathrm{f}}$ and $k_{\mathrm{b}}$ are the first order rate constants of the forward and backward chemical reactions, respectively, $\varepsilon=\frac{k}{f}$ is the chemical kinetic parameter, defined through the cumulative rate constant $k=k_{\mathrm{f}}+k_{\mathrm{b}}$; for the $\mathrm{EC}_{\mathrm{i}}$ mechanism and the $\mathrm{EC}^{\prime}$ catalytic mechanism, the chemical kinetic parameter is defined as $\varepsilon=\frac{k_{\mathrm{f}}}{f}$; for the two-step reaction (EE mechanism) $\omega_{1}=\frac{k_{\mathrm{sur}, 1}}{f}$ and $\omega_{1}=\frac{k_{\mathrm{sur}, 2}}{f}$ and $k_{\mathrm{sur}, 1}$ and $k_{\mathrm{sur}, 2}$ is the rate constant of the first and second electrode reaction, respectively 
concentration $\Gamma^{*}$. For numerical integration, both time and current are incremented, with the serial number of the increments designated with $m$. The time increment is defined as $d=1 / 50 f$, which means that the duration of each potential pulse is divided into 25 time increments. The results are presented in the form of dimensionless current $\Psi=\frac{I}{n F A \Gamma^{3} f}$, where $n$ is the number of electrons, $F$ is the Faraday constant, $A$ is the electrode surface area, and $f$ is the frequency of the potential modulation. The dimensionless current is the function of the dimensionless relative electrode potential $\varphi=\frac{n F}{R T}\left(E-E^{\phi}\right)$, anodic electron transfer coefficient $\alpha_{\mathrm{a}}$, and specific critical kinetic parameters. Here, $E$ is the electrode potential, $E^{\phi}$ is the formal potential of the electrode reaction, $R$ is the gas constant, and $T$ is the thermodynamic temperature. The meaning of the kinetic parameters is explained below Table 2 .

\section{References}

1. Armstrong FA (2002) Voltammetry of proteins. In: Bard AJ, Stratmann M, Wilson GS (eds) Encyclopedia of electrochemistry, vol 9. Wiley VCH, Weinheim

2. Armstrong FA (2002) Voltammetric investigations of iron-sulfur clusters in proteins. In: Brajter-Toth A, Chambers JQ (eds) Electroanalytical methods for biological materials. Marcel Dekker, Basel

3. Armstrong FA (2002) J Chem Soc Dalton 5:661-671

4. Armstrong FA (1997) Applications of voltammetric methods for probing the chemistry of redox proteins. In: Lenaz G, Milazzo G (eds) Bioelectrochemistry: principles and practice, vol. 5. Birkhauser Verlag AG, Basel

5. Barlett PN (2008) Bioelectrochemistry: fundamentals, experimental techniques and application. Wiley, Chichester

6. Jones AK, Lamle SE, Pershad HR, Vincent KA, Albracht SPJ, Armstrong FA (2003) Enzyme Electrokinetics: Electrochemical Studies of the Anaerobic Interconversions between Active and Inactive States of Allochromatium vinosum [NiFe]-hydrogenase. J Am Chem Soc 125:8505-8514

7. Wijma HJ, Jeuken LJC, Verbeet MP, Armstrong FA, Canters GW (2007) Protein film voltammetry of copper-containing nitrite reductase reveals reversible inactivation. J Am Chem Soc 129:8557-8565

8. Mirceski V, Komorsky-Lovric S, Lovric M (2008) In: Scholz F (ed) Square-wave voltammetry, theory and application. Springer, Berlin

9. Gulaboski R, Lovrić M, Mirčeski V, Bogeski I, Hoth M (2008) Protein-film voltammetry: A theoretical study of the temperature effect using square-wave voltammetry. Biophys Chem 137:49-55

10. Hirst J (2006) Elucidating the mechanisms of coupled electron transfer and catalytic reactions by protein film voltammetry. Biochem Biophys Acta 1757:225-239

11. Heering HA, Wiertz FGM, Dekker C, de Vries S (2004) Direct immobilization of native yeast iso-1 cytochrome $\mathrm{c}$ on bare gold: Fast electron relay to redox enzymes and zeptomole protein-film voltammetry. J Am Chem Soc 126:11103-11112

12. Udit AK, Hindoyan N, Hill MG, Arnold FH, Gray HB (2005) Protein-surfactant film voltammetry of wild-type and mutant cytochrome P450 BM3. Inorg Chem 44:4109-4111

13. Sultana N, Schenkman JB, Rusling JF (2005) Protein film electrochemistry of microsomes genetically enriched in human cytochrome P450 monooxygenases. J Am Chem Soc 127:1346013461

14. Léger C, Dementin S, Bertrand P, Rousset M, Guigliarelli B (2004) Inhibition and aerobic inactivation kinetics of Desulfovibrio fructosovorans $\mathrm{NiFe}$ hydrogenase studied by protein film voltammetry. J Am Chem Soc 126:12162-12172

15. Gwyer JD, Richardson DJ, Butt JN (2006) Inhibiting Escherichia coli cytochrome c nitrite reductase: Voltammetry reveals an enzyme equipped for action despite the chemical challenges it may face in vivo. Biochem Soc Trans 34:133-135

16. Lu H, Li Z, Hu N (2003) Direct voltammetry and electrocatalytic properties of catalase incorporated in polyacrylamide hydrogel films. Biophys Chem 104:623-632

17. Shen L, Hu N (2004) Heme proteins with polyamidoamine dendrimer: Direct electrochemistry and electrocatalysis. Biochem Biophys Acta 1608:23-33

18. Li M, He P, Zhang Y, Hu N (2005) An electrochemical investigation of hemoglobin and catalase incorporated in collagen films. Biochem Biophys Acta 1749:43-51

19. Sun W, Gao R, Jiao K (2007) Electrochemistry and electrocatalysis of hemoglobin in nafion/nano- $\mathrm{CaCO}_{3}$ film on a new ionic liquid BPPF6 modified carbon paste electrode. J Phys Chem B 111:4560-4567

20. Stutzmann M, Garrido JA, Eickhoff M, Brandt MS (2006) Direct biofunctionalization of semiconductors: A survey. Phys Stat A 203:3424-3437

21. Härtl A, Schmich E, Garrido JA, Hernando J, Catharino SCR, Walter S, Feulner P, Kromka A, Steinmüller D, Stutzmann M (2004) Protein-modified nanocrystalline diamond thin films for biosensor applications. Nat Mater 3:736-742

22. Barker CD, Reda T, Hirst J (2007) The flavoprotein subcomplex of complex I (NADH: ubiquinone oxidoreductase) from bovine heart mitochondria: Insights into the mechanisms of NADH oxidation and $\mathrm{NAD}+$ reduction from protein film voltammetry. Biochem 46:3454-3464

23. Gwyer JD, Richardson DJ, Butt JN (2004) Resolving complexity in the interactions of redox enzymes and their inhibitors: Contrasting mechanisms for the inhibition of a cytochrome $\mathrm{c}$ nitrite reductase revealed by protein film voltammetry. Biochem 43:15086-15094

24. Munge B, Das SK, Ilagan R, Pendon Z, Yang J, Frank HA, Rusling JF (2003) Electron transfer reactions of redox cofactors in spinach Photosystem I reaction center protein in lipid films on electrodes. J Am Chem Soc 125:12457-12463

25. Bernhardt PV, Santini JM (2006) Protein film voltammetry of arsenite oxidase from the chemolithioautotrophic arsenite-oxidizing bacterium NT-26. Biochem 45:2804-2809

26. Fujita K, Nakamura N, Ohno H, Leigh BS, Niki K, Gray HB, Richards JH (2004) Mimicking protein-protein electron transfer: Voltammetry of Pseudomonas aeruginosa azurin and the Thermus thermophilus $\mathrm{CuA}$ domain at $\omega$-derivatized self-assembled-monolayer gold electrodes. J Am Chem Soc 126:13954-13961

27. Liu A, Wei M, Honma I, Zhou H (2005) Direct electrochemistry of myoglobin in titanate nanotubes film. Anal Chem 77:80688074

28. Salimi A, Sharifi E, Noorbakhsh A, Soltanian S (2006) Direct voltammetry and electrocatalytic properties of hemoglobin immobilized on a glassy carbon electrode modified with nickel oxide nanoparticles. Electrochem Commun 8:1499-1508

29. Aguey-Zinsou K-F, Bernhardt PV, Kappler U, McEwan AG (2003) Direct electrochemistry of a bacterial sulfite dehydrogenase. J Am Chem Soc 125:530-535

30. Frangioni B, Arnoux P, Sabaty M, Pignol D, Bertrand P, Guigliarelli B, Léger C (2004) In Rhodobacter sphaeroides respiratory nitrate reductase, the kinetics of substrate binding 
favors intramolecular electron transfer. J Am Chem Soc 126:1328-1329

31. Astuti Y, Topoglidis E, Briscoe PB, Fantuzzi A, Gilardi G, Durrant JR (2004) Proton-coupled electron transfer of flavodoxin immobilized on nanostructured tin dioxide electrodes: Thermodynamics versus kinetics control of protein redox function. J Am Chem Soc 126:8001-8009

32. Xu Y, Peng W, Liu X, Li G (2004) A new film for the fabrication of an unmediated $\mathrm{H}_{2} \mathrm{O}_{2}$ biosensor. Biosens Bioelectron 20:533-537

33. Udit AK, Hill MG, Gray HB (2006) Electrochemistry of cytochrome P450 BM3 in sodium dodecyl sulfate films. Langmuir 25:10854-10857

34. Fleming BD, Tian Y, Bell SG, Wong L-L, Urlacher V, Hill HAO (2003) Redox properties of cytochrome P450 BM3 measured by direct methods. Eur J Biochem 270:4082-4088

35. Udit AK, Hill MG, Bittner VG, Arnold FH, Gray HB (2004) Reduction of dioxygen catalyzed by pyrene-wired heme domain cytochrome P450 BM3 electrodes. J Am Chem Soc 126:1021810219

36. Zhao L, Liu H, Hu N (2006) Electroactive films of heme proteincoated multiwalled carbon nanotubes. J Coll Int Sci 296:204-211

37. Vincent KA, Belsey NA, Lubitz W, Armstrong FA (2006) Rapid and reversible reactions of $[\mathrm{NiFe}]$-hydrogenases with sulfide. $\mathrm{J}$ Am Chem Soc 128:7448-7449

38. Cai C, Chen J, Lu T (2004) Direct electron transfer of glucose oxidase on the carbon nanotube electrode. Sci China, Ser B Chem 47:113-119

39. Salimi A, Hallaj R, Soltanian S (2007) Immobilization of hemoglobin on electrodeposited cobalt-oxide nanoparticles: Direct voltammetry and electrocatalytic activity. Biophys Chem 130:122-131

40. $\mathrm{Lu} \mathrm{Q}, \mathrm{Hu} \mathrm{S}$ (2006) Studies on direct electron transfer and biocatalytic properties od hemoglobin in polytetrafluoroethylene film. Chem Phys Lett 424:167-171

41. Cai C, Chen J (2004) Direct electron transfer and bioelectrocatalysis of hemoglobin at a carbon nanotube electrode. Anal Biochem 325:285-292

42. Shumyantseva VV, Ivanov YD, Bistolas N, Scheller FW, Archakov AI, Wollenberger U (2004) Direct electron transfer of cytochrome P450 2B4 at electrodes modified with nonionic detergent and colloidal clay nanoparticles. Anal Chem 76:60466052

43. Xie Y, Liu H, Hu N (2007) Layer-by-layer films of hemoglobin or myoglobin assembled with zeolite particles: Electrochemistry and electrocatalysis. Bioelectrochem 70:311-319

44. Cao D, Hu N (2006) Direct electron transfer between hemoglobin and pyrolytic graphite electrodes. Biophys Chem 121:209-217

45. Ye T, Kaur R, Wen X, Bren KL, Elliott SJ (2005) Redox properties of wild-type and heme-binding loop mutants of bacterial cytochromes $\mathrm{C}$ measured by direct electrochemistry. Inorg Chem 24:8999-9006

46. Reeves JH, Song S, Bowden EF (1993) Application of square wave voltammetry to strongly adsorbed quasireversible redox molecules. Anal Chem 65:683-688

47. Saccucci TM, Rusling JF (2001) Modeling square-wave voltammetry of thin protein films using Marcus theory. J Phys Chem B 105:6142-6147

48. Zhang J, Si-X G, Bond AM, Honeychurch MJ, Oldham KB (2005) Novel kinetic and background current selectivity in the even harmonic components of fourier transformed square-wave voltammograms of surface-confined azurin. J Phys Chem B 109:8935-8947

49. Jeuken LJC, Jones AK, Chapman SK, Cecchini G, Armstrong FA (2002) Electron-Transfer Mechanisms through Biological Redox Chains in Multicenter Enzymes. J Am Chem Soc 124:5702-5713
50. Jeuken LJC, McEvoy JP, Armstrong FA (2002) Insights into Gated Electron-Transfer Kinetics at the Electrode-Protein Interface: A Square Wave Voltammetry Study of the Blue Copper Protein Azurin. J Phys Chem B 106:2304-2313

51. Huang H, Hu N, Zeng Y, Zhou G (2002) Elecrochemistry and electrocatalysis with heme proteins in chitosan biopolymer films. Anal Biochem 308:141-151

52. Alcantara K, Munge B, Pendon Z, Frank HA, Rusling JF (2006) Thin film voltammetry of spinach photosystem II. Proton-gated electron transfer involving the Mn4 cluster. J Am Chem Soc 128:14930-14937

53. Xu J, Lu Y, Liu B, Xu C, Kong J (2007) Sensitively probing the cofactor redox species and photo-induced electron transfer of wild-type and pheophytin-replaced photosynthetic proteins reconstituted in self-assembled monolayers. J Solid State Electrochem 11:1689-1695

54. Ma L, Tian Y, Rong Z (2007) Direct electrochemistry of hemoglobin in the hyaluronic acid films. J Biochem Biophys Meth 70:657-662

55. Zhou Y, Hu N, Zeng Y, Rusling JF (2002) Layer-by-layer assembly of ultrathin films of hemoglobin and clay nanoparticles with electrochemical and catalytic activity. Langmuir 18:85738579

56. O'Dea JJ, Osteryoung JG (1993) Characterization of quasireversible surface processes by square-wave voltammetry. Anal Chem 65:3090-3097

57. Komorsky-Lovrić S, Lovrić M (1995) Square-wave voltammetry of quasireversible surface redox reactions. J Electroanal Chem 384:115-122

58. Lovrić M (1991) Modelling of surface electrochemical reactions. Elektrokhimija 27:186-195

59. Komorsky-Lovrić Š, Lovrić M (1995) Measurements of redox kinetics of adsorbed azobenzene by a "quasireversible maximum" in square-wave voltammetry. Electrochim Acta 40:1781-1784

60. Komorsky-Lovrić Š, Lovrić M (1995) Kinetic measurements of a surface confined redox reaction. Anal Chim Acta 305:248-255

61. Mirčeski V, Lovrić M, Jordanoski V (1999) Redox kinetic measurements of probucole using square-wave voltammetry. Electroanal 11:660-663

62. Mirčeski V, Lovrić M, Gulaboski R (2001) Theoretical and experimental study of the surface redox reaction involving interactions between the adsorbed particles under conditions of square-wave voltammetry. J Electroanal Chem 515:91-100

63. Gulaboski R, Mirčeski V, Lovrić M, Bogeski I (2005) Theoretical study of a surface electrode reaction preceded by a homogeneous chemical reaction under conditions of square-wave voltammetry. Electrochem Commun 7:515-522

64. Mirčeski V, Lovrić M (2000) Adsorption effects in squarewave voltammetry of an EC mechanism. Croat Chem Acta 73:305-329

65. Mirčeski V, Gulaboski R (2001) Surface catalytic mechanism in square-wave voltammetry. Electroanalysis 13:1326-1334

66. Mirčeski V, Gulaboski R (2003) The surface catalytic mechanism: A comparative study with square-wave and staircase cyclic voltammetry. J Solid State Electrochem 7:157-165

67. O'Dea JJ, Osteryoung JG (1997) Square-wave voltammetry for two-step surface redox reactions. Anal Chem 69:650-658

68. Mirčeski V, Gulaboski R (2003) A theoretical and experimental study of a two-step quasireversible surface redox reaction by square-wave voltammetry. Croat Chem Acta 76:37-48

69. Gulaboski R (2009) Surface ECE mechanism in protein film voltammetry-a theoretical study under conditions of square-wave voltammetry. J Solid State Electrochem 13:1015-1024

70. Mirceski V, Lovric M (1997) Split square-wave voltammograms of surface redox reactions. Electroanal 9:1283-1287 
71. Halliwell B, Gutteridge JM (2001) Free radicals in biology and medicine, 3rd edn. Oxford University Press, New York

72. Bard AJ (2008) Toward single enzyme molecule electrochemistry. ACS Nano 2:2437-2440

73. Amemiya S, Bard AJ, Fan F-RF, Mirkin MV, Unwin PR (2008) Scanning electrochemical microscopy. Ann Rev Anal Chem 1:95131

74. McEvoy JP, Brudvig GW (2006) Water-splitting chemistry of photosystem II. Chem Rev 106:4455-4483
75. Aguey-Zinsou KF, Bernhardt PV, Leimkuehler S (2003) Protein Film Voltammetry of Rhodobacter Capsulatus Xanthine Dehydrogenase. J Am Chem Soc 125:15352-15358

76. Gulaboski R, Mihajlov L (2011) Catalytic mechanism in successive two-step protein-film voltammetry. Theoretical study in square-wave voltammetry. Biophys Chem 155:1-9

77. Nicholson RS (1968) A method based on polynomial approximations for numerical solution of volterra integral equations. J Electroanal Chem 16:145-151 